1. MBBS, FCPS Urology Assistant Professor Urology Jinnah Postgraduate Medical Center Jinnah Sindh Medical University

Karachi.

2. MBBS, FCPS Urology Assistant Professor Urology Baqai Medical University Karachi.

3. MBBS, FCPS Urology

Senior Registrar Urology CMCH Larkana.

4. MBBS, FCPS Urology Senior Registrar Peoples University of Medical and Health Sciences for Women Nawabshah.

5. MBBS, FCPS Urology Senior Registrar Urology Isra University Campus Altibri Medical College and Hospital Karachi.

6. MBBS, M.S (General Surgery) Senior Registrar Urology Shaheed Mohtarma Benazir Bhutto Medical College Lyari Karachi.

Correspondence Address:

Dr. Arif Ali

Assistant Professor Urology

Jinnah Postgraduate Medical Center

Jinnah Sindh Medical University

Karachi.

dr.arifshaikh.jpmc@gmail.com

Article received on:

17/09/2019

Accepted for publication:

26/12/2019

\section{TO DETERMINE THE OUTCOME OF EXTRACORPORPOREAL SHOCK WAVES LITHOTRIPSY FOR HIGH DENSITY RENAL STONE ON NON-CONTRAST COMPUTED TOMOGRAPHY.}

\begin{abstract}
Arif Ali ${ }^{1}$, Bilal Suria ${ }^{2}$, Safiullah Sohu ${ }^{3}$, Mumtaz Ali Chandio", Suhail Dilawar ${ }^{5}$, Mahmood Ahmed Memon ${ }^{6}$
ABSTRACT... Objectives: To determine the outcome of extracorporporeal shock waves lithotripsy for high density renal stone on non-contrast computed tomography. Study Design: Descriptive study. Setting: Urology Department of Chanka Medical College Hospital (CMCH) Larkana. Period: $1^{\text {st }}$ November 2017 to $31^{\text {st }}$ October 2018. Material \& Method: Patients in the age range of 25-75 years were selected, irrespective of their gender. After 12 weeks final outcome of ESWL was measured by performing plain X-ray KUB films before and after procedure. Satisfactory outcome was defined as stone clearance in $<3$ sessions of the procedure. Results: According to our inclusion and exclusion criteria 122 patients were selected for ESWL. Among them there were $41.8(n=51)$ females and $58.1 \%(n=71)$ males. The mean age of the patients was found to be $34.08+9.53$ years. Approximately more than half of the patients $57.4 \%(n=70)$ patients were present in the age group of in $\leq 35$ years. The mean size of the stone was $1.51+$ $0.5 \mathrm{~cm}$ whereas mean stone density as scan was $772+22.2 \mathrm{HU}$. Patients were having renal or ureteric stones for mean duration of $2.07+0.31$ months. Around $69.7 \%$ of patients had renal stones and $30.3 \%$ of patients had ureteric stones. Stone clearance was found in $58.2 \%$ $(n=71)$ of the patients. Conclusion: Non-contrast enhanced CT scan is the most frequently used investigation to diagnose kidney stones and decide its treatment modality. Outcome of ESWL also depends on various factors as mentioned in the study.
\end{abstract}

Key words: $\quad$ Extracorporporeal Shock Waves Lithotripsy, Renal Stones, Ureteric Stones.

Article Citation: Ali A, Suria B, Sohu S, Chandio MA, Dilawar S, Memon MA. To determine the outcome of extracorporporeal shock waves lithotripsy for high density renal stone on non-contrast computed tomography. Professional Med J 2020; 27(2):403-406. DOI: 10.29309/TPMJ/2020.27.2.4265

\section{INTRODUCTION}

Extracorporeal shock wave lithotripsy (ESWL) is the most commonly used treatment modality for urinary tract stones. ${ }^{1}$ The diagnosis of urinary stones is made by X-ray, ultrasound and CT scans. CT scan without contrast is found to be the investigation of choice for evaluating urinary stones. $^{2}$ The size and location of stone found on CT scan is used to determine whether patient is suitable for ESWL or not. ${ }^{3}$ Various studies have shown the positive predictive factors for ESWL and ESWL was done on the basis of findings of CT scan without contrast. ${ }^{4}$ Success of ESWL depends on following factors like disc skin calculus (DSC), density of the calculus itself and body mass index (BMI) of the patient. Decreased disc skin calculus and decreased density of the calculus are positive predictive factors for ESWL. ${ }^{5,6}$ CT scan without contrast is used to identify causes of radiolucent filling defects. It does so by measuring density of the radiolucent filling defects in Hounsfield units. The density of calculi is greater than the density of tumors or blood. ${ }^{7,8}$ Plain X-ray of abdomen and pelvis are also used to identify renal stones, but they cannot distinguish between different densities. CT scan without contrast is the most preferred investigation in patients with renal colic as it can distinguish density differences of $<0.5 \% .^{9}$ It also determines the fragility of the stone by its density. The outcome of ESWL is also affected by its fragility like more fragile stones requires only one session of ESWL. ${ }^{10,11}$ Stones in the urinary tract are made up of uric acid, phosphates and rarely cysteine. The composition of stone can predict the fragility of the stone; hence it ultimately affects the clinical outcome of ESWL. Patients with calculi of $>750 \mathrm{HU}$ approximately $70 \%$ of patients require 
more than three sessions of ESWL. Around 37\% of patients had complete clearance after only one session of ESWL. A study showed that $77 \%$ of the calculi with a diameter of $>1.1 \mathrm{~cm}$ needed three or more than three sessions of ESWL and only $60 \%$ of the patients were cleared of stones. ${ }^{12}$ However, different studies show different rates of clearance and variable outcomes compared to the number of ESWL sessions. ${ }^{13}$ There is no consensus on definition of success in ESWL. Some authors define success as absence of stones 6 weeks after ESWL while others define it as absence of fragments of $<4 \mathrm{~mm}$ in three months after ESWL. ${ }^{9}$ The aim of our study is to evaluate outcome of ESWL in kidney stones with density of $>750 \mathrm{HU}$ and significance of non-contrast enhanced CT scan for assessment of kidney stones.

\section{MATERIAL METHODS}

This descriptive study was conducted in Urology Department of Chanka Medical College Hospital $(\mathrm{CMCH})$ Larkana in the duration of 1 st November 2017 to 31st October 2018. Inclusion criteria for the study was patients with solitary renal or ureteric calculi of size $0.5-2 \mathrm{~cm}$, stone confirmed by intravenous urography, high intensity renal stones of $>750 \mathrm{HU}$ on non-contrast enhanced CT scan, duration of disease must be less than three months. The age of patients must fall in the range of 25-50 years, irrespective of their gender. Patients with inferior calyceal stone or ureteric stone $>1 \mathrm{~cm}$, having single functioning kidney, existing congenital kidney anomaly, disease requiring stent placement, development of steinstrasse during therapy, coexistent bleeding disorder, patient having $\mathrm{BMI}$ of $>30 \mathrm{~kg} / \mathrm{m} 2$ were excluded from the study.

Patients who matched our inclusion criteria were made part of the study. Written and informed consent was taken from every patient before procedure. Pros and cons of the procedure were explained to the patients. It was made sure that patient's identity would be kept anonymous during the whole study. All the data was collected on questionnaire including demographic information, duration of disease; diagnosis, no of ESWL sessions. Statistical analysis was performed using SPSS version 17. All patients enrolled in the study underwent ESWL under analgesia and sedation. Patients were being sent home and called for follow-up after 12 weeks. After 12 weeks final outcome of ESWL was measured by performing plain X-ray KUB films before and after procedure. Satisfactory outcome was defined as stone clearance in $<3$ sessions of ESWL.

\section{RESULTS}

According to our inclusion and exclusion criteria 122 patients were selected for ESWL. Among them there were $41.8(n=51)$ females and $58.1 \%$ $(n=71)$ males. The mean age of the patients was found to be $34.08+9.53$ years. Approximately more than half of the patients $57.4 \%(n=70)$ patients were present in the age group of in $\leq 35$ years. The mean size of the stone was $1.51+$ $0.5 \mathrm{~cm}$ whereas mean stone density as scan was $772+22.2 \mathrm{HU}$. Patients were having renal or ureteric stones for mean duration of $2.07+$ 0.31 months. Around $69.7 \%$ of patients had renal stones and $30.3 \%$ of patients had ureteric stones. Stone clearance was found in $58.2 \% \quad(n=71)$ of the patients. There were $26(21.3 \%)$ patients with 2 ESWL sessions, 33(27\%) patients with 3 ESWL sessions and 63(51.6\%) patients with 4 ESWL sessions. Satisfactory outcome as defined above was found in $52(42.6 \%)$ patients.

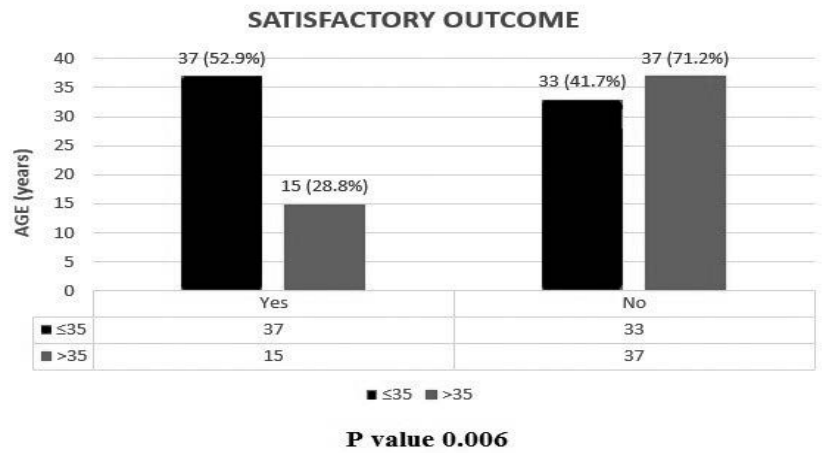

Figure-1. Age and satisfactory outcome $n=122$

\begin{tabular}{|l|c|c|c|c|}
\hline \multirow{2}{*}{$\begin{array}{c}\text { Stone Size } \\
\text { (in cm) }\end{array}$} & \multicolumn{2}{|c|}{$\begin{array}{c}\text { Satisfactory } \\
\text { Outcome }\end{array}$} & Total & \multicolumn{1}{|c|}{$\begin{array}{c}\text { P- } \\
\text { Value }\end{array}$} \\
\cline { 1 - 3 } & Yes & No & & \\
\hline$\leq 1$ & $12(20.3)$ & $47(79.7)$ & $59(100)$ & \\
\hline$>1$ & $40(63.5)$ & $23(36.5)$ & $63(100)$ & 0.001 \\
\hline Total & $52(42.6)$ & $70(57.4)$ & $122(100)$ & \\
\hline
\end{tabular}

Table-I. Stone size and satisfactory outcome $n=122$ 


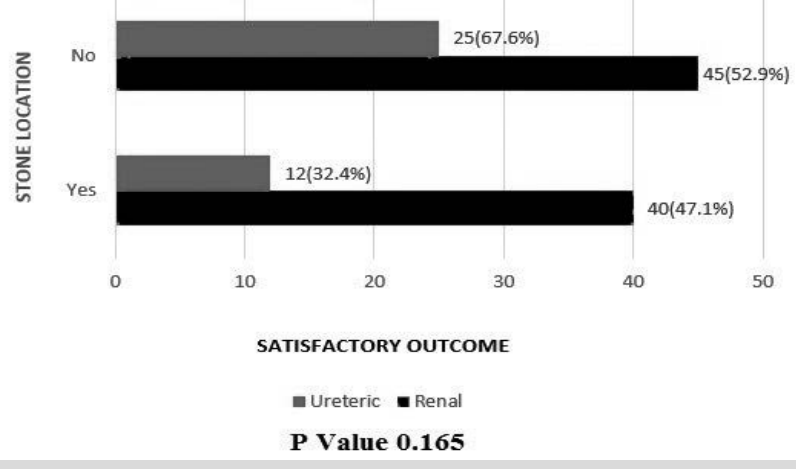

Figure-2. Stone location and satisfactory outcome $n=122$

\section{DISCUSSION}

The outcome of lithotripsy is reduced in proportion to the increasing BMl of the patient. Studies have shown that patients having more body fat and skin to stone distance of $>10 \mathrm{~cm}$ show decreased response to ESWL. ${ }^{14}$ The results of lithotripsy cannot be compared because the results are somewhat dependent on the operator experience and treatment protocol. Different lithotripters used in ESWL also provide variable outcomes..$^{15}$ In our study stone clearance was found in $58.2 \%$ of the patients, while $42.6 \%$ of the patients showed satisfactory results. A retrospective review done to evaluate treatment outcomes of patients with renal or ureteric calculi patients undergoing general anesthesia had $87 \%$ stone clearance rate compared to patients receiving sedation after three months of ESWL. Patients receiving intravenous sedation only had a stone clearance rate of $55 \%(p<0.001)$. Hence it shows that treatment outcome was improved after proper analgesic dose. ${ }^{16}$ Another study showed that patients undergoing lithotripsy had greater incidence of developing diabetes mellitus and new onset hypertension. ${ }^{14}$

A prospective study conducted on stone clearance after ESWL showed that along with age intrarenal resistive index increases and hence stone clearance is decreased in patients aged 60 years or older. ${ }^{17}$ In this study patients treated with only ESWL and no surgical intervention were followed on long term by survey and $58.9 \%$ patients responded. It was found that there was increased risk of developing hypertension after
ESWL compared to the control group treated conservatively. Patients receiving bilateral ESWL treatment were more prone to develop hypertension in future $(p=0.033)$. Also found that patients receiving ESWL therapy developed diabetes mellitus at an earlier age than compared to control group on long term follow-up. The development of diabetes mellitus was also proportional to the number of shocks given and intensity of lithotripter. It is also noted that after ESWL pancreatic enzymes like lipase, amylase are raised up to one week of the procedure in proximal ureteral and renal stones, while no episode of acute pancreatitis was found in lower ureteral stones. ${ }^{18}$

According to previous studies conducted CT scan without contrast is one of the most widely used investigation for kidney stones. It predicts the size, density, fragility and possible outcome of lithotripsy; various studies have described its importance for diagnosing any mass in the kidney. ${ }^{19}$ As various factors predict outcome of ESWL like age, density of stone, recurrent kidney disease, intensity and number of sessions of lithotripter. There is different success rates (46\%$91 \%)$ published in different studies according to the long term follow-up.

\section{CONCLUSION}

Non-contrast enhanced CT scan is the most frequently used investigation to diagnose kidney stones and decide its treatment modality. Outcome of ESWL also depends on various factors as mentioned in the study.

\section{Copyright $\odot 26$ Dec, 2019.}

\section{REFERENCES}

1. Argyropoulos A, Tolley D. Optimizing shock wave lithotripsy in the 21st century. Eur Urol. 2007; 52:34452.

2. Nakasato T, Morita J, Ogawa $Y$. Evaluation of Hounsfield Units as a predictive factor for the outcome of extracorporeal shock wave lithotripsy and stone composition. Urolithiasis. 2015; 43:69.

3. Dalla Palma L, Pozzi-Mucelli R, Stacul F. Present day imaging in patients with renal colic. Eur Radiol. 2001; 11:4-7. 
4. El-Nahas A, El-Assmy A, Mansour O, Sheir K. A prospective multivariate analysis of factors predicting stone disintegration by extracorporeal shock wave lithotripsy: The value of high-resolution noncontrast computed tomography. Eur Urol. 2007; 51:1688---93.

5. Pareek G, Hedican S, Lee Jr F, Nakada S. Shock wave lithotripsy success determined by skin-to-stone distance on computed tomography. Urology. 2005; 66:941-4.

6. Perks A, Schuler T, Lee J, Ghiculete D, Chung D, D'A Honey $R$, et al. Stone attenuation and skin-to-stone distance on computed tomography predicts for stone fragmentation by shock wave lithotripsy. Urology. 2008; 72:765--9.

7. Federle MP, McAninch JW, Kaiser JA, Goodman PC, Roberts J, Mall JC. Computed tomography of urinary calculi. AJR Am J Roentgenol 1981; 136:255-8.

8. Parienty RA, Ducellier R, Pradel J, Lubrano JM, Coquille $F$, Richard F. Diagnostic value of CT numbers in pelvocalyceal filling defects. Radiology. 1982; 145:743-7.

9. Fielding JR, Steele G, Fox A, Heller H, Loughlin KR. Spiral computerized tomography in the evaluation of acute flank pain: A replacement for excretory urography. J Urol 1997; 157: 2071-3.

10. Dretler SP. Stone fragility - a new therapeutic distinction. J Urol 1988; 139:1124-7.

11. Mostafavi MR, Ernst RD, Saltzman B. Accurate determination of chemical composition of urinary calculi by spiral computerized tomography. J Urol 1998; 159: 673-5.
12. Gupta NP, Ansari MS, Kesarvani P, Kapoor A, Mukhopadhyay S. Role of computed tomography with no contrast medium enhancement in predicting the outcome of extracorporeal shock wave lithotripsy for urinary calculi. BJU. 2005.1285-8.

13. Coz F, Orvieto M, Bustos M, Lyng R, Stein C, Hinrichs A, et al. Extracorporeal shockwave lithotripsy of $\mathbf{2 0 0 0}$ urinary calculi with the modulith SL-20: Success and failure according to size and location of stones. J Endourol. 2000; 14:239-46.

14. Ng CF, McLornan L, Thompson TJ, Tolley DA. Comparison of 2 generations of piezoelectric lithotriptors using matched pair analysis. The Journal of urology. 2004 Nov 1;172(5):1887-91.

15. Krambeck AE, Gettman MT, Rohlinger AL et al: Diabetes mellitus and hypertension associated with shock wave lithotripsy of renal and proximal ureteral stones at 19 years of follow-up. J Urol 2006; 175:1742.

16. Sorensen C, Chandhoke P, Moore M, Wolf C, Sarram A. Comparison of intravenous sedation versus general anesthesia on the efficacy of the Doli $\mathbf{5 0}$ lithotriptor. J Urol. 2002; 168: 35-37.

17. Janetschek G, Frauscher F, Knapp R et al: New onset hypertension after extracorporeal shock wave lithotripsy: age related incidence and prediction by intrarenal resistive index. J Urol 1997; 158: 346.

18. Abe $H$, Nisimura $T$, Osawa $S$ et al: Acute pancreatitis caused by extracorporeal shock wave lithotripsy for bilateral renal pelvic calculi. Int J Urol 2000; 7: 65.

19. Fani P, Patlas MN, Monteiro S, Katz DS. Non-contrast MDCT for ureteral calculi and alternative diagnoses: Yield in adult women vs in adult men. Current problems in diagnostic radiology. 2019 Mar 1; 48(2):148-51.

\begin{tabular}{|c|c|c|c|}
\hline \multicolumn{4}{|c|}{ AUTHORSHIP AND CONTRIBUTION DECLARATION } \\
\hline Sr. \# & Author(s) Full Name & Contribution to the paper & Author(s) Signature \\
\hline 1 & Bilal Suria & $\begin{array}{l}\text { Conception and design, } \\
\text { Statistical expertise, Critical } \\
\text { revision of the article for } \\
\text { important intellectual content. } \\
\text { Drafting of the article, Critical } \\
\text { revision of the article for } \\
\text { important intellectual content. }\end{array}$ & \\
\hline 3 & Safiullah Sohu & Data collection. & \\
\hline 4 & Mumtaz Ali Chandio & Data analysis. & \\
\hline 5 & Suhail Dilawar & $\begin{array}{l}\text { Literature review and Proof } \\
\text { reading. }\end{array}$ & \\
\hline 6 & Mahmood Ahmed Memon & $\begin{array}{l}\text { Literature review and } \\
\text { referencing. }\end{array}$ & \\
\hline
\end{tabular}

